\title{
TUBERCULOSIS PREVENTIVE THERAPY IN HIV INFECTION
}

\author{
CONSENSUS GUIDELINES FROM A WORKSHOP, \\ 29 - 30 OCTOBER 1999
}

\section{HIV Clinicians Society of Southern Africa \\ Corresponding author: G Maartens, Infectious Diseases Unit, Department of Medicine, University of Cape Town (e-mail:gary@curie.uct.ac.za)}

HIV infection causes progressive deterioration of cell-mediated immunity that results in an inability to contain pre-existing dormant infection with and new exposure to Mycobacterium tuberculosis. The risk of tuberculosis (TB) in HIV-infected individuals who have been exposed to $M$. tuberculosis, as assessed by a positive tuberculin skin test, is approximately $10 \%$ per annum. TB is the commonest cause of morbidity and mortality in HIV-infected patients in South Africa, as is the case elsewhere in sub-Saharan Africa. In areas of high HIV prevalence TB incidence has increased alarmingly. It is estimated that approximately $50 \%$ of new adult cases of TB in South Africa are attributable to HIV.

TB enhances HIV replication in vitro by activating the immune system.' There is conflicting evidence from epidemiological studies that this leads to accelerated HIV disease progression.' However, one metaanalysis of trials of preventive therapy $y^{2}$ showed improved survival in tuberculin skin test-positive patients, which strongly supports the view that TB does accelerate HIV disease progression.

The best approach to reduce the increasing TB caseload attributable to HIV infection is to improve the TB cure rates (Fig. 1). ${ }^{3}$ Strategies to control HIV infection are also vital, but are beyond the scope of this guideline. TB preventive therapy directed at known HIV-infected individuals will not significantly reduce the incidence of $T B$ in the community, but it is an intervention that benefits HIV-infected individuals. TB clinics in South Africa are striving to improve cure rates and to institute the DOTS (directly observed therapy, short-course) strategy. Progress is being made, but the clinics are generally over-extended. Because of this load on the clinics and the operational difficulties involved in implementing a TB preventive therapy programme for HIV-infected patients, ${ }^{4}$ preventive therapy cannot at present be provided by the national TB programme.

This guideline is intended to provide an evidence-based approach to the provision of $T B$ preventive therapy for HIV-infected patients in South Africa. The setting in which preventive therapy is given will range from private prac-

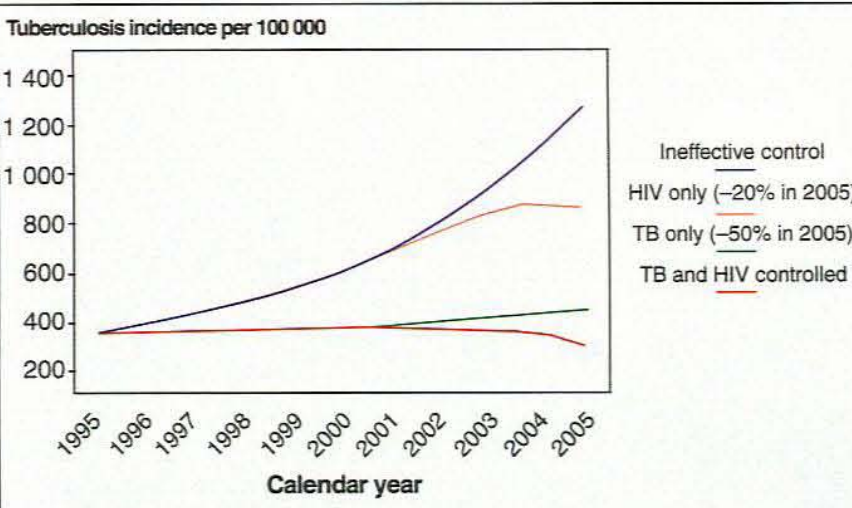

Fig. 1. Model of TB incidence in South Africa from 1995 to 2005. If $T B$ cure rates pertaining in 1995 are not improved there will be a 4.5-fold increase in TB cases. If HIV transmission is reduced by $20 \%$ there will be a 3-fold increase, if TB cure rates are optimal there will be a 1.6-fold increase, and if both HIV and TB cure rates improve the TB caseload will decrease. (Courtesy of Fourie and Weyer, Medical Research Council National Tuberculosis Research Programme.)

tices through to the evolving strategy of state-run voluntary counselling and testing centres.

\section{EFFICACY OF PREVENTIVE THERAPY}

Preventive therapy for TB has been shown to be effective in HIV-infected patients at risk for TB. Regimens are discussed below. Trials have shown that only patients with evidence of TB infection, as assessed by a positive tuberculin skin test (in the setting of HIV infection a Mantoux $\geq 5 \mathrm{~mm}$ is considered positive), benefit from preventive therapy (Fig. 2). Among these patients the reduction in incidence of TB is about 60\%. ${ }^{6}$ Preventive therapy also prolongs survival, but once again the benefit is only seen in patients who are tuberculin skin test-positive. ${ }^{2}$ In areas where there is a high prevalence of TB and where Mantoux tests cannot be performed it may be reasonable to offer preventive therapy to all HIVinfected individuals, ${ }^{6}$ but this does not apply to most areas in South Africa.

Although TB occurs with increasing frequency as patients become more immune suppressed, it may present at any level of immune suppression. Thus, unlike most opportunistic infections, there is no level of immunity above which the risk is low. Preventive therapy should therefore be offered irrespective of the CD4+ 


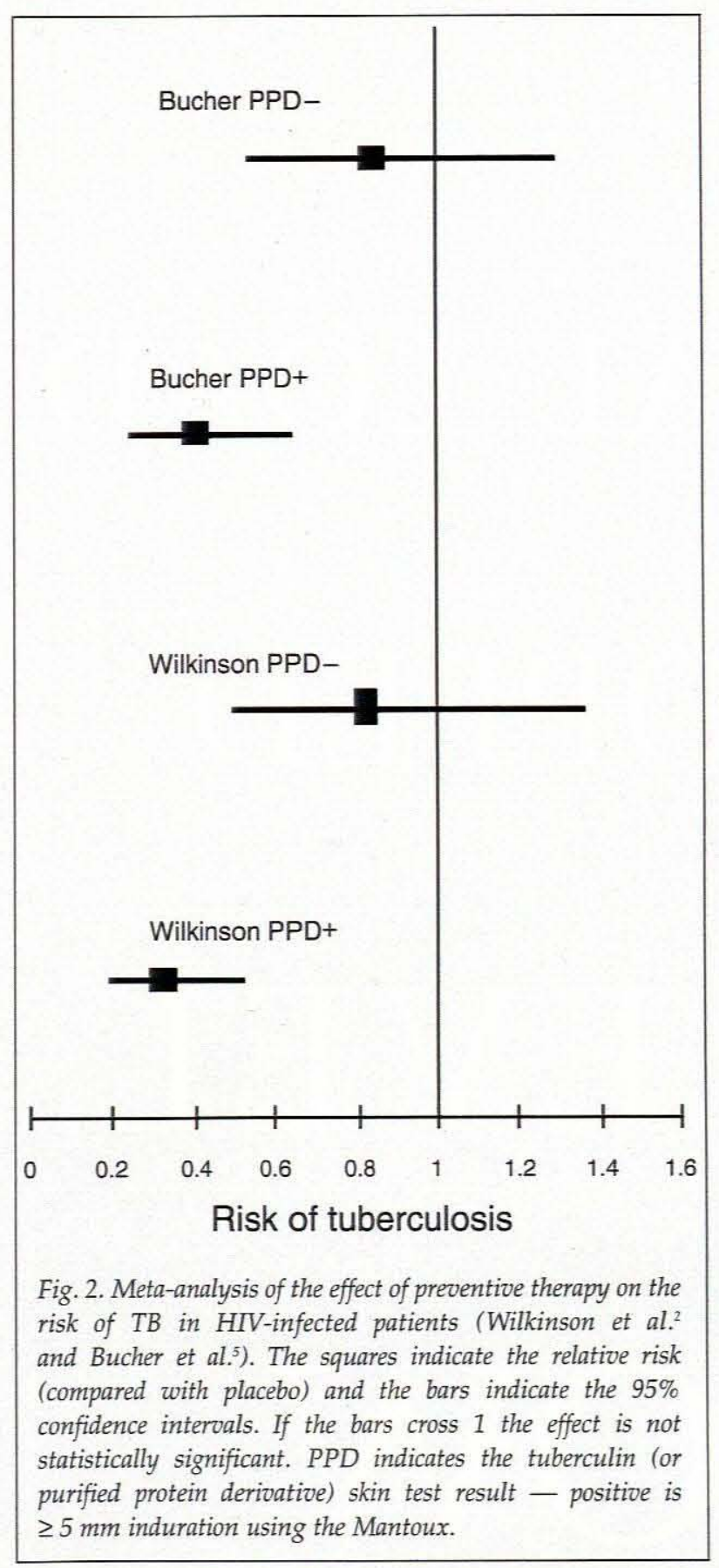

lymphocyte count or clinical evidence of immune suppression. Treatment of many opportunistic infections in HIV-infected patients consists of acute therapy followed by secondary prophylaxis to prevent recurrences. However, recurrence rates after conventional short-course (6 months) antituberculosis therapy are similar for patients with and without HIV infection. ${ }^{8}$ Secondary prophylaxis is therefore not indicated after treating TB in HIV-infected patients.

Preventive therapy is well tolerated, with few serious adverse events reported in clinical trials. Compliance in clinical trials as well as in the field is in the range of $60-80 \%$.

\section{EXCLUDING ACTIVE TB}

It is essential to exclude active TB in every patient before starting therapy as resistance could emerge in patients given a single drug for preventive therapy. Patients should be specifically asked about symptoms of TB - all patients with symptoms need further evaluation. Two sputum samples from all patients who can produce sputum should be sent for microscopy for acid-fast bacilli. Where facilities and resources permit, mycobacterial culture should also be done. A chest radiograph should be done in all cases before starting preventive therapy. Patients with abnormal chest radiography need to be evaluated further.

\section{WHO IS ELIGIBLE FOR PREVENTIVE THERAPY?}

As discussed above, trials clearly show that the benefit of preventive therapy is limited to those with a positive Mantoux. However, several other categories of patients would benefit from preventive therapy irrespective of tuberculin skin test status.

Those in contact with TB sufferers should be offered preventive therapy, irrespective of whether the sputum smear is positive or negative in the index case. This applies particularly to children who have TB contacts. HIV-infected infants are at the highest risk. ${ }^{9}$ Newborns whose mothers have TB should be screened for congenital TB - preferably by a paediatrician. If this is excluded then preventive therapy should be offered. BCG vaccination should be deferred until after the course of preventive therapy (BCG vaccination is not recommended for infants who have HIV-related symptoms).

Health care workers with an exposure history (this will apply to nearly all in South Africa) are a particularly high-risk group ${ }^{10}$ and often have ongoing exposure to TB. Attempts should be made to move the health care worker to a lower risk area, but this is often difficult to achieve partly because moving a staff member may breach confidentiality. If the health care worker has ongoing exposure, then repeat courses of preventive therapy should be considered every year.

HIV-infected patients living in high-risk dormitory conditions, such as in prisons or mines, are at very high risk of developing TB and should be considered for preventive therapy irrespective of tuberculin skin test status.

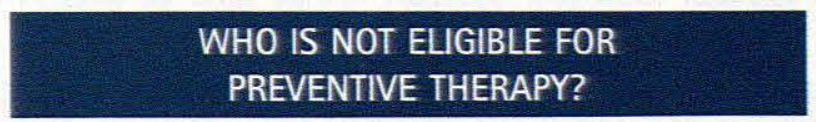

Because all of the drugs used for preventive therapy can cause hepatotoxicity, patients with active alcohol abuse or liver disease should not be offered preventive therapy. As noted above, patients who have been treated for TB should not be given preventive therapy. However, patients with TB that was treated at least 2 years previously may be considered for preventive therapy. This guideline is not based on published evidence but on the premise that re-infection with TB is likely to be common in South Africa. 


\section{RECOMMENDED REGIMENS}

The standard regimen for preventive therapy is isoniazid (INH) for 6 months. The dosage is $5 \mathrm{mg} / \mathrm{kg} /$ day (maximum $300 \mathrm{mg} /$ day) or $15 \mathrm{mg} / \mathrm{kg} /$ dose (maximum 900 $\mathrm{mg}$ given twice weekly. The latter regimen is suitable for supervised therapy.

Combination regimens containing rifampicin administered for shorter periods of time are equally effective. Rifampicin plus pyrazinamide for 2 months or rifampicin plus INH for 3 months have both been shown to be as effective as INH for 6 months. ${ }^{6}$ Rifampicin plus pyrazinamide plus INH was not as well tolerated in one study, ${ }_{1}$ and was therefore not as effective. The use of rifampicin for preventive therapy is, however, strongly discouraged unless this is given in a formulation that includes the other drug or drugs, as this could cause resistance with disastrous consequences for the TB control programme. Rifampicin plus INH is available as a combined preparation in South Africa and is recommended for 3 months (doses are the same as those used for treating TB). Currently $T B$ clinics will only provide this to children. Rifampicin-containing regimens should preferably be administered as directly observed therapy.

There is insufficient evidence to allow for a recommended regimen for contacts of multidrug-resistant TB.

\section{MONITORING PATIENTS ON PREVENTIVE THERAPY}

Patients on preventive therapy should only be supplied with 1 month of therapy at a time and monitored monthly for drug toxicity as well as signs or symptoms of TB. It is unnecessary to monitor with serial liver function tests unless the patient has underlying liver disease. Peripheral neuropathy is a side-effect of INH and is a common feature in late HIV disease. It is therefore prudent to administer pyridoxine while patients are receiving $\mathrm{INH}$ preventive therapy.

\section{LIMITATIONS OF EXISTING EVIDENCE ON THE BENEFIT OF PREVENTIVE THERAPY}

Published studies have either excluded patients with advanced disease or included only a small number of such patients. The risk of TB increases with advancing immune suppression.? These patients are more likely to have a negative tuberculin skin test. Consequently the evidence that preventive therapy is only beneficial in patients with a positive tuberculin skin test may not apply to patients with advanced disease.

The duration of benefit of preventive therapy has not been adequately studied. Two studies have reported that the benefit of preventive therapy was lost 18 months after preventive therapy.12,13 There are research projects underway to address this issue.

Hoechst Marion Roussell sponsored the workshop with an unconditional educational grant.
1. Del Amo J, Malin AS, Pozniak A, De Cock KM. Does tuberculosis accelerate the progression of HIV disease? Evidence from basic science and epidemiology. AIDS 1999; 13: 1151-1158.

2. Wilkinson D, Squire SB, Garner P. Effect of preventive treatment for tuberculosis in adults infected with HIV: systematic review of randomised placebo controlled trials. BMJ 1998; 317:625-629.

3. Fourie PB, Weyer K. Anticipated impact of HIV on the tuberculosis epidemic in South Africa. In: TB Control in South Africa - Joint Programme Review 1996 (WHO/TB/96.208). Geneva: WHO, June 1996.

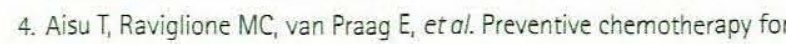
HIV-associated tuberculosis in Uganda: an operational assessment at a voluntary counselling and testing centre. AIDS 1995; 9: 267-273.

5. Bucher $H C$, Griffith LE, Guyatt $G H$, et al. Isoniazid prophylaxis for tuberculosis in HIV infection: a meta-analysis of randomized controlled trials. AIDS 1999; 13: 501-507.

6. WHO Global Tuberculosis Programme/UNAIDS. Preventive therapy against tuberculosis in people living with HIV. Wkly Epidemiol Rec 1999; 74: 385-398

7. Wood R, Maartens $G$, Lombard Cl. Risk factors for developing tuberculosis in HIV-1-infected adults from communities with a low or very high incidence of tuberculosis. I Acquir Immune Defic Syndr Hum Retrovirol 2000; 23: 75-80.

8. Connolly C, Reid A, Davies G, Sturm W, McAdam KP, Wilkinson D. Relapse and mortality among HIV-infected and uninfected patients with tuberculosis successfully treated with twice weekly directly observed therapy in rural South Africa. AIDS 1999; 13: 1543-1547.

9. Coovadia $H M_{\text {, Jeena }} P_{1}$ Wilkinson D. Childhood human immunodeficiency virus and tuberculosis co-infections: reconciling conflicting data. Int J Tuberc Lung Dis 1998; 2: 844-851.

10. Harries AD, Nyirenda TE, Banerjee A, Boeree MJ, Salaniponi FM. Tuberculosis in health care workers in Malawi. Trans R Soc Trop Med Hyg 1999; $93: 32-35$.

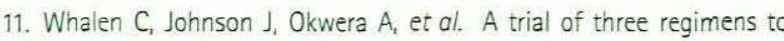
prevent tuberculosis in Ugandan adults infected with the human immunodeficiency virus. N Engl J Med 1997; 337: 801-808.

12. Wadhawan $D$, Hira $S$, Mwansa $N$, Sunkutu $R$, Adera $T$, Perine $P$. Preventive tuberculosis chemotherapy with isoniazid among patients infected with HIV-1. 9th International Conference on AIDS, Berlin Germany, 1993

13. Mwinga $A$, Hosp $M$, Godfrey-Faussett $P$, et al. Twice weekly tuberculosis preventive therapy in HIV infection in Zambia. AIDS 1998 12: $2447-2457$

\section{APPENDIX I. WORKSHOP PARTICIPANTS}

L Blumberg (South African Institute for Medical Research and Infectious Diseases Society of Southern Africa),

G Churchyard (Mining Industry),

B Fourie (Medical Research Council),

V Gathiram (Department of Medicine,

University of Natal),

H Hausler (Department of Health),

P Jeena (Department of Paediatrics, University of Natal),

D Martin (HIV Clinicians Society),

R Matji (Department of Health),

P Onyebujoh (Medical Research Council),

M Steinberg (Managed Care).

Reprinted from the South African Medical Journal (2000; 90: 592 594), with permission 


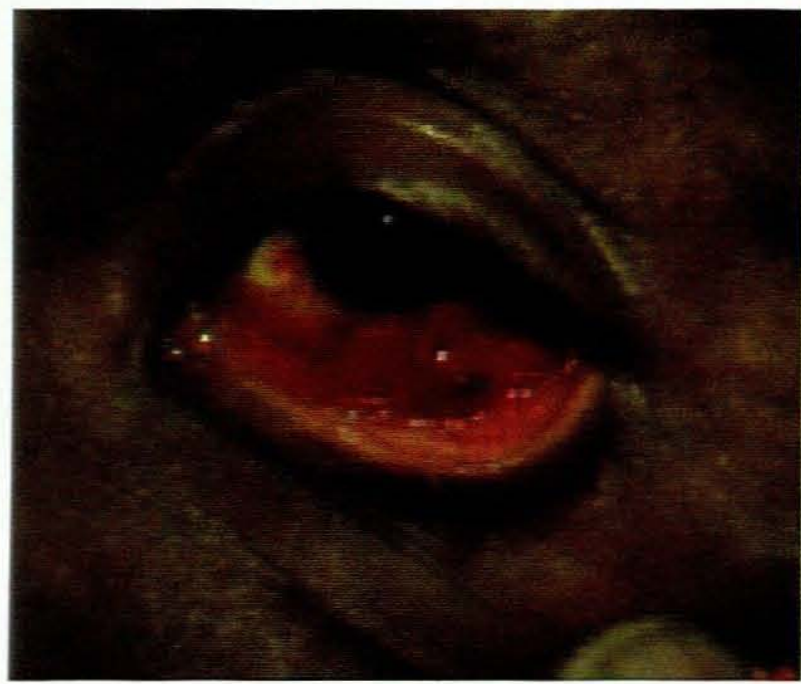

FIG. 10.

Kaposi's sarcoma of the conjuctiva.

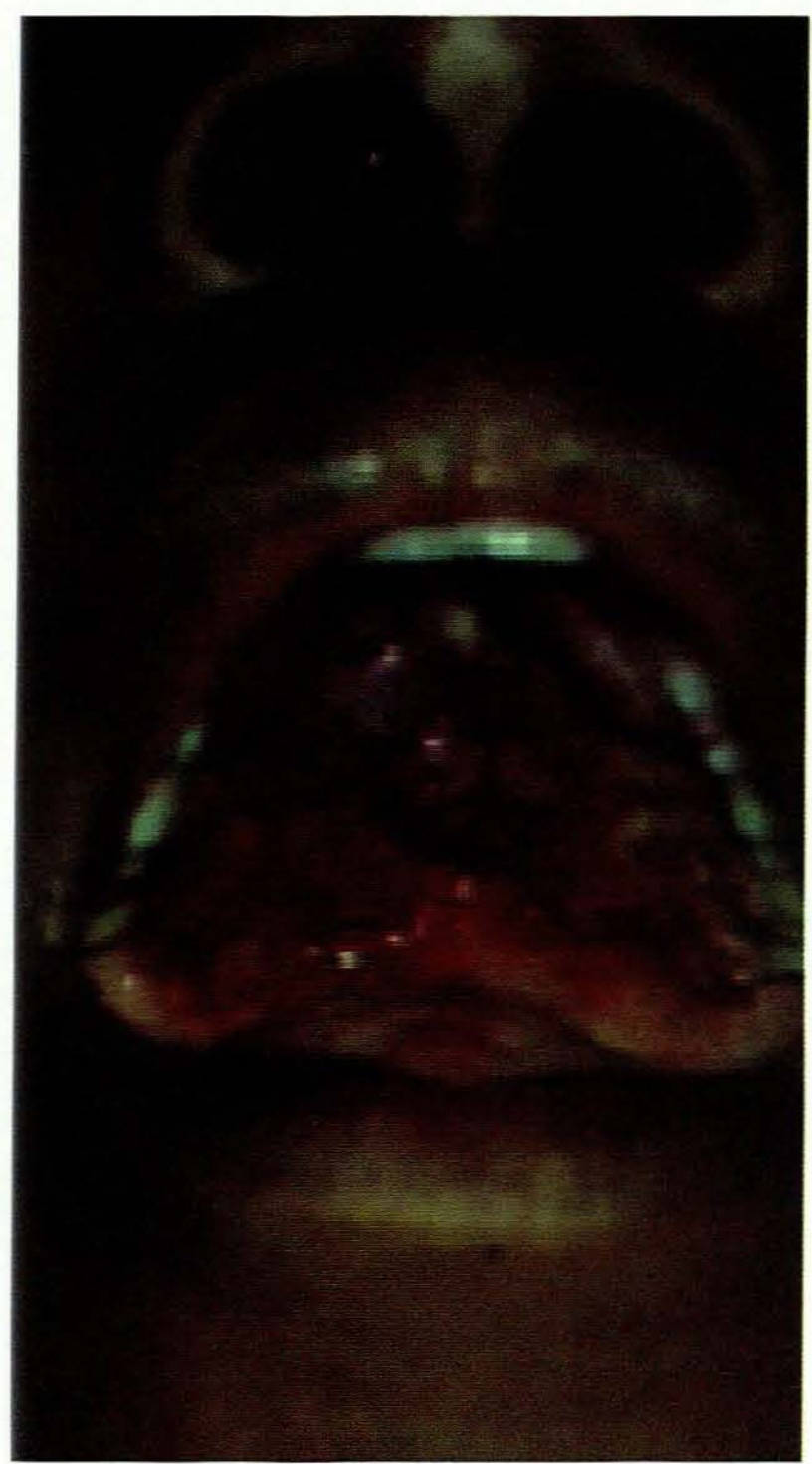

FIG. 12.

Kaposi's sarcoma of the buccal mucosa

2. Non-Hodgkin's lymphoma of the kidney is a common cause of unilateral/bilateral ureteric obstruction due to retroperitoneal involvement of the tumour. It is of an undifferentiated B-cell type and follows a very aggressive course' (Fig. 13).

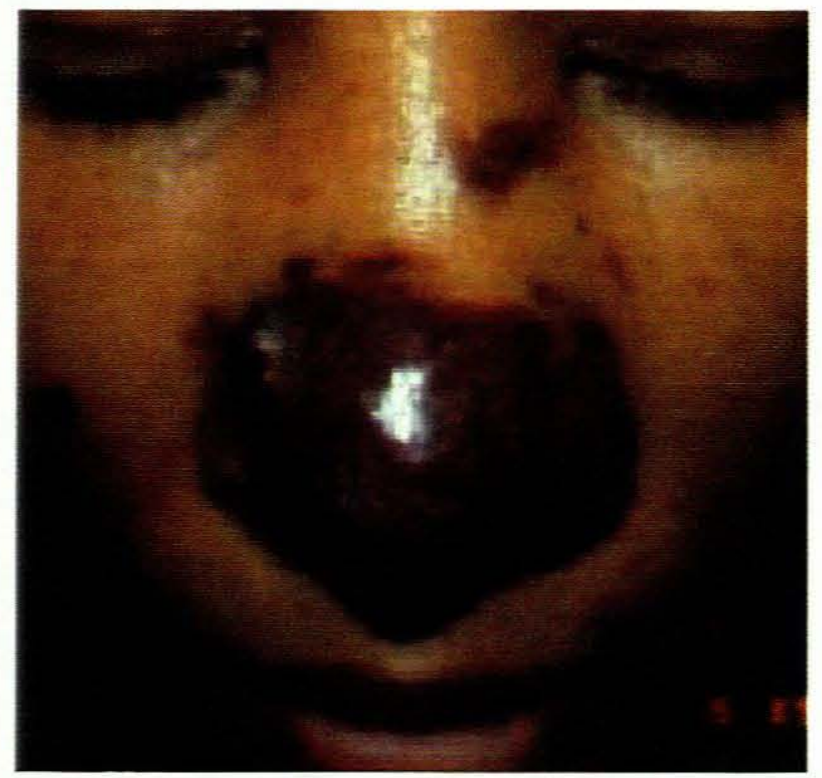

FIG. 11.

Kaposi's sarcoma of the nose.

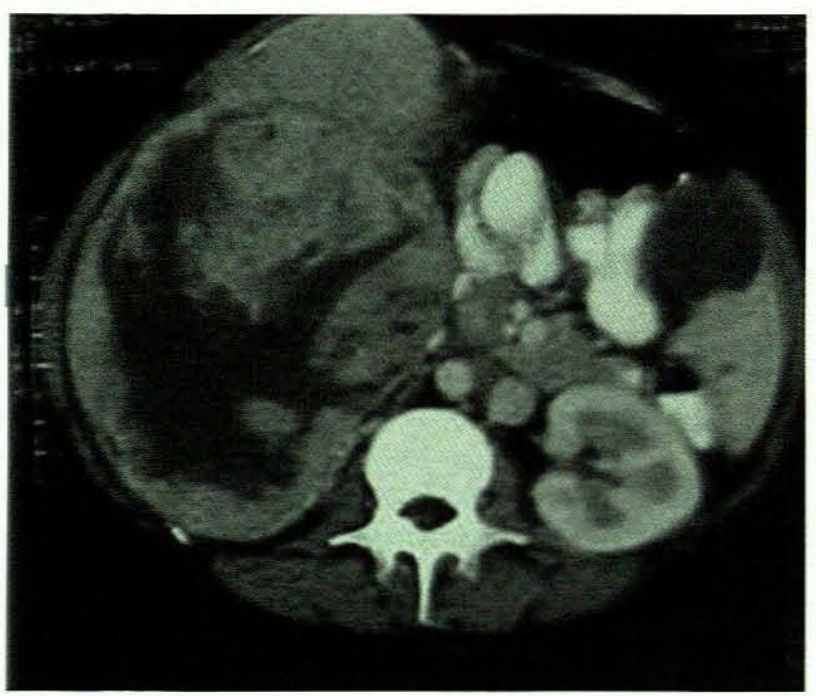

FIG. 13.

CT scan of the abdomen, showing a renal mass in an HIV-infected patient. Histological examination revealed B-cell lymphoma of the kidney.

3. Primary testicular lymphoma in young HIV-infected men is an entirely new condition and was rarely diagnosed previously except in old patients. It is of a high pathological grade and associated with a poor prognosis. $^{8}$

4. Carcinoma of the penis has also been diagnosed in increasing numbers.

We hypothesise that the presence of other sexually transmitted diseases (STDs), particularly genital herpes, may increase the risk for acquisition of HIV. STDs that inflame or ulcerate squamous epithelium or STDs that infect columnar epithelium, possibly promoting squamous metaplasia, may influence susceptibility to genital human papilloma virus infection (HPV). These changes of the epithelium may be responsible for changes that lead to malignant growth (Figs $14-16$ ). 


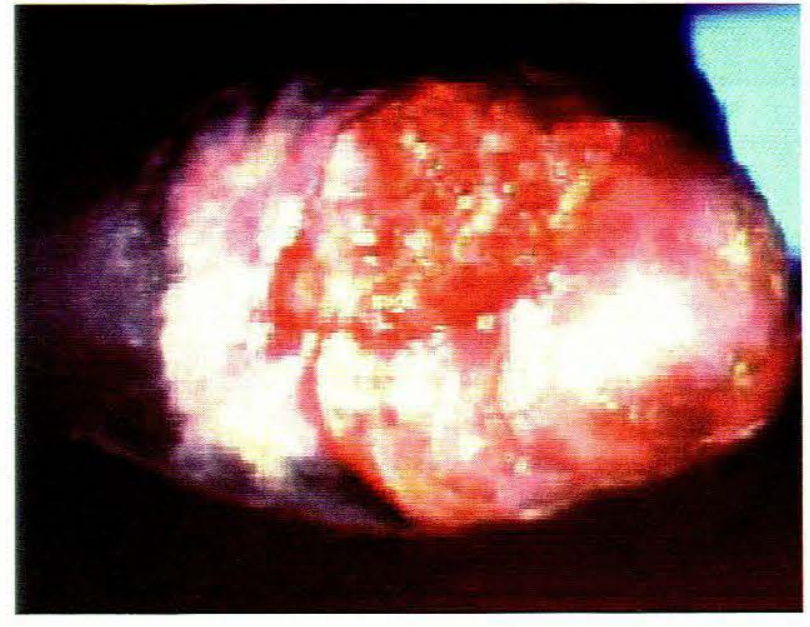

FIG. 14.

Ulcerative lesion of the glans. Histological examination revealed penile squamous cell carcinoma.

\section{IMPAIRED RENAL FUNCTION}

HIVAN is associated with unique clinical and pathological features. Clinical series have discovered proteinuria and rapidly progressive irreversible renal failure in up to $40 \%$ of patients.

HIVAN affects the glomeruli, tubules and interstitium simultaneously. Grossly, the kidneys are enlarged with an oedematous and widened cortex and medulla.

Microscopically, focal segmental glomerulosclerosis (FSGS) is the predominant lesion encountered. FSGS is associated with an increase in visceral epithelial cells, mesangial matrix and cellurality. Tubular interstitial involvement is marked by tubular dilatation with protein casts, nephrocalcinosis and interstitial fibrosis.

Other lesions reported include immune complex nephropathies such as membranoproliferative glomerulonephritis, diffuse proliferative GN, membranous nephropathy and $\lg A$ nephropathy.

CT findings revealed global enlargement of both kidneys without hydronephrosis or cortical scarring, with increased attenuation of the medullary portion.

FSGS progresses rapidly to end-stage renal failure over 8 - 16 weeks. Death is most commonly related to complications and infections associated with AIDS.

\section{VOIDING DYSFUNCTION}

Incidence of neurological complications in AIDS is estimated at $30-40 \%$ of patients.

AIDS affects both the central and peripheral nervous systems.

Toxoplasmosis, the most common CNS opportunistic infection, is recognised in up to $14 \%$ of AIDS patients with neurological disease. CNS toxoplasmosis was present in $40 \%$ of AIDS patients with

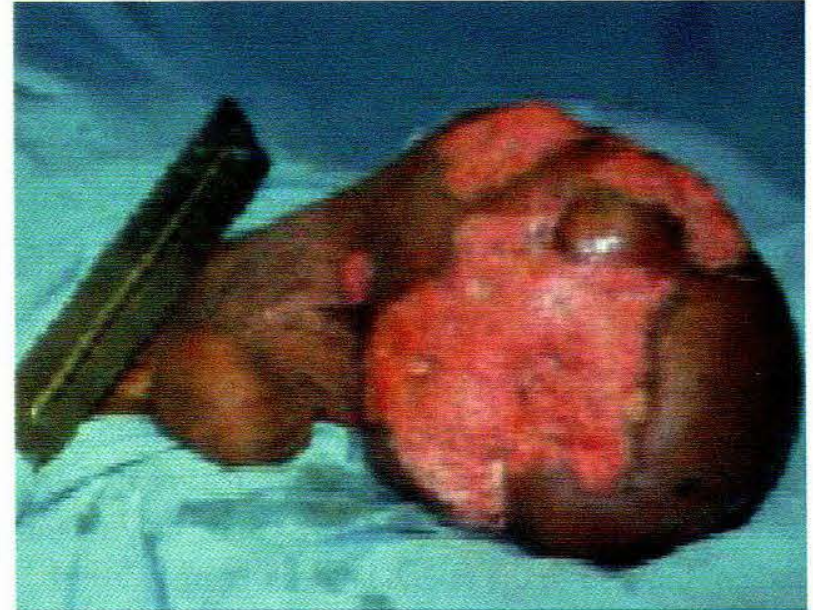

FIG. 15.

Huge ulcerating mass of the precuce - penile cancer.

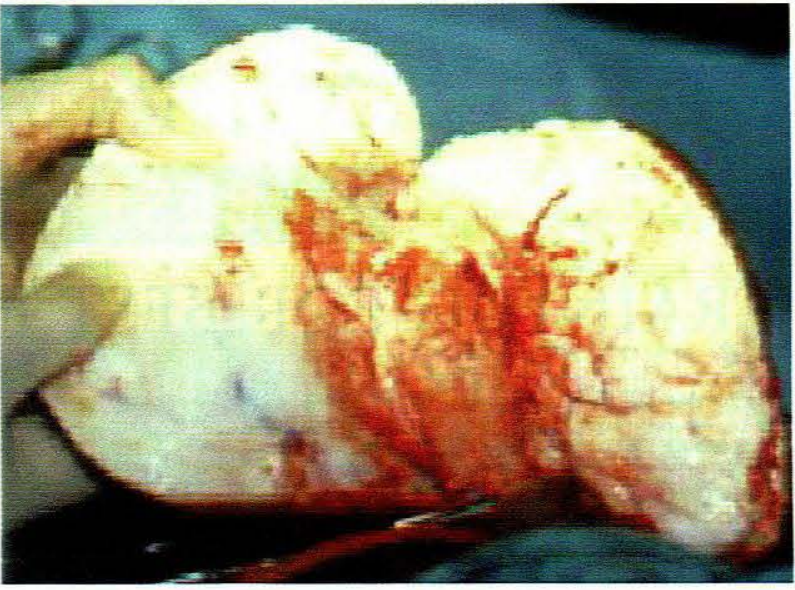

Fig. 16.

Cut section of the mass illustrated in Fig. 15 after excision.

neurogenic bladder. Urinary retention is the most common presenting symptom, followed by urge incontinence.

On urodynamic evaluation, areflexia was the most common finding followed by detrusor hyperreflexia and then hyporeflexia.

It has been suggested that the variation between urodynamic findings may reflect the extent of CNS involvement.

As the clinical course is progressive, initially affecting the thoracic (sympathetic outflow) and later the other areas of the spinal cord producing loss of the sacral reflex arc (parasympathetic outflow), the urodynamic abnormalities would also be progressive with detrusor hyperreflexia eventually becoming hyporeflexic.

In many developed countries the voiding problems experienced by HIV-infected patients have been attributed to the side-effects of the various antiviral drugs. Since none of the patients at KEH had been on antiviral treatment, it can be assumed that the voiding abnormalities found on urodynamic studies are solely the result of HIV infection. 


\section{CONCLUSION}

At our hospital the current infection control policy is to regard all patients as potentially infected. Careful attention to sexual history, especially in patients with unusual genitourinary conditions, may alert the urologist to the possibility of AIDS.

Diagnosis of these syndromes should lead to careful consideration of the relative risks and benefits of surgery or other forms of invasive treatment. Such procedures may pose significant risks not only to the patient but also to the attending health care workers.

Thanks to Professor R Chetty for the slides on CMVcystitis (Fig. 7).

\section{REFERENCES}

1. AIDS foundation of South Africa. www.aids.ora.za
2. Catanese AJ, Tessler AN, Morales P. AIDS and the urologist, Part 1: urologic manifestations of AIDS. AUA Ujdate Series 1989; 8: 1-7.

3. Benson MC, Kaplan MS, OToole K, Romagnoli M. Report of cytomegalovirus cystitis and a review of other genitourinary manifestations of the aquired immune deficiency syndrome. J Urol 1988; 140: 153-154

4. Bayne D, Wise GJ. Kaposi's sarcoma of the penis as an initial urological manifestation of AIDS. A report of two cases. Urol Int 1991; 46: 235-237.

5. Kedes D, Operskalski E, Busch $M_{1}$ Kohn R, Flood J, Ganem D. The seroepidemiology of human herpesvirus8 (Kaposi's sarcoma-associated herpesvirus): Distribution of infections in KS risk groups and evidence for sexual transmission Nat Med 1996; 2(8): 918-924.

6. Lowe FC, Lattimer DG, Metroka CE. Kaposis sarcoma of the penis in patients with aquired immuno-deficiency syndrome. J Urol 1989; 142: 1475-1477.

7. Mohler JL, Jarow JP, Marshall FF: Unusual urological presentations of acquired immune deficiency syndrome: large cell lymphoma. I Urol 1987: 138: $627-629$

8. Wilson WT, Frenkel E, Vuitch F, Sagalowsky AL Testicular tumors in men with human immunodeficiency virus. J Urol 1992; 147: 1038-1040.

9. Coleburn NH, Scholes $\mathrm{NV}$, Lowe FC. Renal failure in patients with AIDS related complex. Urology 1991; 37: 523-527.

10. Khan Z, Singh WK, Yang WC. Neurogenic bladder in acquired immune deficiency syndrome (AIDS). Urology 1992; 40; 289-291.

\section{BEST PRACTICES}

\section{TRAINING FOR BEST HIV CARE PRACTICES IN THE PUBLIC HEALTH SERVICES}

Developing health care professionals' knowledge and skills in HIV and AIDS care will bring about positive changes in their attitude towards caring for HIV-infected patients.

The South African National Department of Health has published policy guidelines to assist with identifying best practices for HIV care in adults and children, for managing TB with HIV and for preventing vertical HIV transmission.

In some instances these guidelines are being adapted or alternatively locally relevant guidelines are being developed within the provincial services. Either way, there is an urgent need to ensure that appropriate ongoing training takes place so that the guidance provided can be effectively put into practice. A countrywide training programme is being planned by the National Department of Health to assist provinces with providing in-service health care worker education and training that will become institutionalised with time

The Diflucan Partnership Programme, described in 'Horizons', through providing both knowledge of how to implement AIDS care practices in caring for AIDS patients affected by cryptococcal meningitis or oesophageal candidiasis, and the means to treat these conditions, should incentivise professionals who might be frustrated by the lack of resources to treat these conditions. It also should begin the broader process of re-examining how AIDS patients are being managed in the public sector, and lead to more informed consideration of what is acceptable care, resulting in better standards of care.

The opportunity is now available to systematically begin health care worker training, conducted in partnership with provincial programmes and facilitated by national resources and assistance.

The process of training will contribute to the professional development of participating health professionals and should lead to measurable changes in their attitudes towards caring for HIV-infected patients and in the quality of care provided. Diflucan Partnership Programme Best Care Practices training is also seen as the point of entry into a longer-term process of countrywide health worker training that will encourage best clinical practices in HIV/AIDS care across the care continuum within all levels of public health facilities.

A faculty of doctor and nurse trainers, the AIDS Care Faculty, is being established to enable broad participation in this process and to leverage the limited expertise available into producing a cascade of information and knowledge sharing. The Faculty will be a 'virtual network' comprising experienced professionals who might have institutional affiliations, or be independent. It aims to cut across traditional institutional and geographical barriers to build a national intellectual resource base that will become an extremely valuable regional asset with time. Faculty members will be both supported and incentivised in their participation and in undertaking trainingrelated activities.

As the process of training develops further and eventually becomes systematised, it is hoped that needs-led requests will come from individual groups of health care workers, institutions or managers to have specific training activities conducted when and where it suits them. This will be coordinated and supported from the National HIV Best Care Practices Training Centre. For more information about participating in this initiative, either as a potential Faculty member or as a training participant, please call $+27(0) 11$ 4842500

\section{SHAUN CONWAY}

Executive Director

IAPAC Southern Africa Regional Office 